\title{
HISTÓRIA E HISTORIOGRAFIA DA EDUCAÇÃO - A BAHIA E SUAS CONEXÕES COM OS ESTUDOS REGIONAIS E NACIONAIS
}

\section{RESUMO}

Jaci Maria Ferraz de Menezes ${ }^{1}$

Este texto busca discutir o tema História e historiografia da Educação no Brasil e na Bahia. Tomamos como questão principal a seguinte: Teriam os estudos sobre História da Educação começado, no Brasil, com a implantação da pós-graduação? Ficariam de fora de nosso esforço de análise a produção de pesquisadores e organismos de pesquisa públicos e privados, tais como o INEP, o Centro Brasileira de Pesquisas Educacionais, com sua rede de Centros Regionais que a ele eram ligados, o IPEA, a Fundação para o Desenvolvimento da Ciência na Bahia (FDCBa), a Fundação CPE e o Instituto Anísio Teixeira, entre tantos outros? Fizemos anteriormente esta reflexão sobre História e Historiografia da Educação em momentos anteriores; tanto no Encontro de Pesquisa em Educação das regiões Norte Nordeste de 2007 em Salvador como no III Encontro Norte Nordeste de História da Educação, realizado em 2010 em Salvador. Nestes dois momentos, nos debruçamos sobre a relação entre questões de pesquisa e metodologias utilizadas para enfrentá-las; e no segundo, a reflexão sobre o nosso fazer, no Grupo Memória e na REDEMEMO, para enfrentar a questão do trato de uma documentação de referência sobre Educação na Bahia. Concluímos que nosso entendimento de que a pesquisa sobre História da Educação na Bahia - e no Brasil - não começa nem se esgota com as Universidades e seus Programas de pós-Graduação. Centros diversos de pesquisa e pesquisadores diversos produziram e ajudaram a construir este conhecimento.

Palavras-chave: Pesquisa Historiográfica; História da Educação; Educação na Bahia.

\section{HISTORY AND EDUCATION HISTORIOGRAPHY - BAHIA AND CONNECTIONS WITH REGIONAL AND NATIONAL STUDIES}

\begin{abstract}
This paper discusses the History and Education of historiography in Brazil and Bahia. We take as main issue as follows: Did the studies of History of Education started in Brazil with graduate deployment? Would be left out of our analysis effort the production of researchers and public and private research organizations, such as INEP, the Brazilian Center for Educational Research, with its network of Regional Centers that it was connected, the IPEA, the Foundation for Development of Science in Bahia (FDCBa), CPE Foundation and the Institute Anísio Teixeira, among many others? We did earlier this reflection on Education History and Historiography in earlier times; both in Education of the North Northeast 2007 Research Meeting in Salvador as in the Third Meeting of North Northeast History of Education, held in 2010 in Salvador. In these two moments, we look back on the relationship between research questions and methodologies used to address them; and second, to reflect on our doing, the Group Memory and REDEMEMO, to address the issue of treatment of a reference documentation on Education in Bahia. We conclude that our understanding that the research on History of Education in Bahia - and Brazil - does not begin nor end with the universities and their post-graduate programs. several research centers and several researchers have produced and helped build this knowledge.
\end{abstract}

Keywords: historical research; History of Education; Education in Bahia. 


\section{Introdução}

Este texto tem como ponto central a discussão sobre "História e historiografia da Educação no Brasil"; nela tomamos como questão principal a seguinte: Teriam os estudos sobre História da Educação começado, no Brasil, com a implantação da pós-graduação? Ficariam de fora de nosso esforço de análise a produção de pesquisadores e organismos de pesquisa públicos e privados, tais como o INEP, o Centro Brasileira de Pesquisas Educacionais, com sua rede de Centros Regionais que a ele eram ligados, o IPEA, a Fundação para o Desenvolvimento da Ciência na Bahia (FDCBa), a Fundação CPE e o Instituto Anísio Teixeira, entre tantos outros?

Fizemos anteriormente esta reflexão sobre História e Historiografia da Educação em momentos anteriores; tanto no Encontro de Pesquisa em Educação das regiões Norte Nordeste de 2007 em Salvador como no III Encontro Norte Nordeste de História da Educação, realizado em 2010 em Salvador. Nestes dois momentos, nos debruçamos sobre a relação entre questões de pesquisa e metodologias utilizadas para enfrentá-las; e no segundo, a reflexão sobre o nosso fazer, no Grupo Memória e na REDEMEMO, para enfrentar a questão do trato de uma documentação de referência sobre Educação na Bahia.

Hoje, revisitando o tema, entendemos que a importância das redes de pesquisa está sendo cada vez mais reafirmada, não só como espaço de troca de resultados de pesquisa, mas também como espaço de apropriação, pelos diversos grupos e pesquisadores da História da Educação, dos resultados de pesquisa dos demais colegas; portanto, como espaço de aprendizado e de reflexão sobre a interelação entre as diversas gerações de pesquisadores.

Colocada a questão, podemos então retomar o percurso, neste novo momento de encontro que a X Jornada do HISTEDBR nos possibilita. Como norma, buscando a clareza sobre o que seria História - as coisas feitas e a narração das coisas feitas; a perspectiva de que as narrativas são múltiplas, diversos os pontos de vista; e que o trabalho com a Historiografia nos deve permitir, (reunindo e analisando os traços, os vestígios, os documentos - aqui tomados com um significado amplo) possamos recompor " a teia de múltiplas determinações" . Tomando o cuidado para que a leitura dos sinais seja feita também nas entrelinhas, interpretando os indícios e procurando o não dito. Neste momento novo, queremos introduzir uma reflexão sobre os nossos predecessores; e apontar para experiências importantes das quais participamos, como o Programa de Cooperação Acadêmica com as nossas parceiras, a Universidade Estadual de Campinas, a Pontifícia Universidade Católica de S. Paulo e com a nossa co-irmã, a Universidade Estadual do Sudoeste da Bahia.

Entendemos que chegar a uma Historiografia só nos será possível na medida em que se possa reunir e analisar um conjunto de evidências que permita recompor um traçado no tempo e no espaço sobre Educação, Educação Brasileira, Educação na Bahia. E este esforço é cada vez mais um esforço coletivo, até porque nos interessa tanto conhecer os esforços pela educação no espaço escolar como as formas não escolares. Nesta mesa, gostaria de apresentar o percurso e alguns resultados de pesquisa sobre História da 
Educação na Bahia, que podem nos ajudar a entender o trabalho do pesquisador, da História da educação, as ferramentas que usa, a construção da documentação de base para o seu trabalho. Tomamos como figura central o professor Dr. Luis Henrique Dias Tavares. Menos que uma homenagem, o que queremos é trazer para o foco de nossas discussões o pesquisador disciplinado, sistemático, permanentemente aliado das classes populares que se colocou durante todo o seu percurso de intelectual a serviço da (re)construção de sua história. Em especial, os resultados de seu trabalho a serviço do INEP- CRINEP-BA.

\section{Pesquisando sobre História da Educação na Bahia.}

O Grupo Memória foi formado na Fundação CPE - depois Centro de Planejamento e Estudos da Bahia - CEPLAB, em 1979. Contou, neste momento, com a assessoria da professora Dilza Maria Andrade Atta e com o suporte de pesquisa e documentação da equipe do setor de Documentação e Biblioteca - depois Biblioteca Rômulo Almeida - sob a coordenação da bibliotecária Nelcy Mendonça, que nos assessorou no levantamento de documentação junto ao Arquivo Público do Estado da Bahia, além de outros acervos da Bahia. Com a extinção do CEPLAB, em 1980, foi continuada a rede de pesquisadores então formada, entre aqueles que continuaram na SEPLANTEC - grupo de Indicadores Sociais, - com outros que foram deslocados para a Secretaria da Educação e para a Secretaria do Trabalho e Bem-Estar Social.

Trabalhou desde então o grupo Memória em torno ao tema da democratização da educação na Bahia, com foco no período de 1920 a 1980, procurando ver em que medida se podia falar nesta democratização, entendida como: a ampliação do acesso à educação via matrículas nos diversos níveis de ensino; como mudança nas relações de poder no interior da escola e na mudança nos conteúdos e métodos com que se ensinava e aprendia. Formando uma Memória da Educação como resultado, procurou reunir a Legislação Educacional do período, organizar uma Bibliografia sobre Educação na Bahia e conhecer as experiências de inovação propostas e postas em prática no sistema educacional baiano. Estes trabalhos, inconclusos na ocasião, foram por nós publicados na Universidade do Estado da Bahia.

Como resultado de entrevistas realizadas num período de pesquisa exploratória, tomamos como momentos principais para o estudo da Educação na Bahia (1920 a 1980), as gestões de Anísio Teixeira (1925-1928 e 1947-1951); Isaías Alves, (1937 a 1942) e Luis Navarro de Britto (1967 a 1969). Organizamos um Seminário sobre Experiências Inovadoras na Educação da Bahia na década de 1960, que nos ensinou que o elo de ligação entre as mesmas era feito pelos professores, que conseguiam sobreviver às mudanças de regime, além de formar novas gerações - a nós, inclusive. Nas transformações sofridas em 1980 na estrutura do Estado via leis delegadas, a CPE e a CEPLAB, foram extintas; o grupo Memória foi formalmente extinto e seus membros dispersos em outras Secretarias de Estado.

Como resultado dos trabalhos de então, publicamos em 1984 um texto intitulado o "Acesso à Educação na Bahia", analisando os dados estatísticos provenientes dos Censos 
Demográficos de 1920 a 1980 e dados de matrícula. Ao constatar a pequena dimensão dos que tinham acesso à escola e a sua paulatina eliminação ao longo de série e níveis de ensino, passamos a nos perguntar quem eram os que ficavam de fora, quem eram os excluídos. O Censo de 1980 e a reintrodução do quesito de cor da pele no seu questionário nos permitiu retomar revelações já presentes em 1940 e 1950 - os de fora eram os pretos e os pardos - ou seja, os negros. Com os dados de renda apurados no Censo de 1980, foi possível ver que estes eram também os pobres e pretos ${ }^{2} \mathrm{e}^{3}$.

Reunidos de volta na Secretaria de Educação do Estado, em 1987(em novo “intervalo democrático"), os trabalhos do grupo tiveram continuidade no Instituto Anísio Teixeira, entre 1987 e 1990, resultando em diversas publicações, inclusive uma Série Memória da Educação, que publicou biobibliografias de Anísio Teixeira, Isaías Alves e Navarro de Brito, elaborada por membros da Biblioteca Rômulo Almeida - CPE durante o período de 1979 - 1980; uma monografia sobre Isaías Alves de Almeida, elaborada pela professora Maria Alba Guedes Machado Mello, hoje membro do Conselho Estadual de Educação; e um volume especial de sua série Memória dos Cadernos do IAT, sobre Anísio Teixeira. Nele, publicamos um texto intitulado "Anísio Teixeira, Secretário da Educação na Bahia; ou porque não se democratiza a Educação na Bahia?" ${ }^{4}$.

O IAT publicou, também uma monografia sobre as Classes Especiais do Centro de Ciência da Bahia - CECIBA, no Colégio Estadual da Bahia, parte ampliada de um depoimento coordenado pela professora Leda Jesuino no Seminário de Experiências Inovadoras da década de $1960 .^{5}$ Participa o grupo, no IAT, da constituição da Fundação Anísio Teixeira, da organização de uma Conferência Estadual de Educação e da proposição do Plano Decenal de Educação, após a aprovação da nova Constituição do Estado da Bahia, depois de ter ajudado na discussão de seu capítulo sobre Educação. Idem, na Lei Orgânica do Município de Salvador.

Parte do grupo inicial se reaglutinou na Universidade do Estado da Bahia em 1997. Professores concursados dessa Universidade, já amadurecidos em sua formação como mestres e doutores, o grupo trabalhou agora em torno à proposição e formação do Programa de Pós-graduação em Educação e Contemporaneidade, do qual serviu como uma de suas bases de pesquisa, tendo trabalhado com o apoio do CNPQ no Programa Norte Nordeste de Apoio à Pesquisa e à Pós-graduação, a partir de 1997. Nesta ocasião, beneficiando-se da condição multicampi da universidade, o Projeto de Pesquisa tomou a forma de projeto integrado, formando naquele momento cinco núcleos: Itaberaba, Teixeira de Freitas, Juazeiro, Senhor do Bonfim e Alagoinhas. Outros núcleos se agregaram depois.

Através do Programa de Qualificação Institucional - PQI CAPES, realizado em conjunto com a UFRN, a USP e a UFRGS, a UNEB formou oito doutores; outros ainda foram formados com o apoio institucional do programa PAC, da própria Instituição; e outros, através do programa de bolsas da FAPESB. A formação desses doutores e outros mestres, das diversas unidades da UNEB, foi possível construir um conhecimento, parcial ainda, sobre aspectos regionais de realização da educação. Com base nos resultados do PQI, fizemos recente publicação de livro - da Coleção Memória da Educação, pela EDUNEB.

$\mathrm{Na} \mathrm{CPE}$, na Secretaria da Educação e agora na UNEB, tivemos como preocupação refletir sobre as relações entre Estado e fazer educativo; sobre a proposição e manutenção 
da Escola Pública como espaço (desejado) de acesso à educação pelas classes populares e as diversas correntes filosóficas e pedagógicas que se embatiam em torno ao desejo de maior e melhor aprendizagem. Realizamos, na ocasião da constituição do grupo, um seminário permanente de leitura e discussão de textos a respeito, para melhor entender este embate não como sucessão linear, mas como conflito pedagógico e político de visões de mundo e de interesses de grupos. Prioritariamente, trabalhamos sobre a República. Inicialmente, como período de 1920 a 1980. Na sua retomada, o grupo constituído na UNEB ampliou o período de análise. Os colegas trabalharam também outros períodos. É o caso, por exemplo, da professora Dra. Silvia Leite, hoje na UFBA, que trabalhou toda a Legislação do ensino superior, desde o Império.

Mais recentemente, a professora Dra Elizabete Conceição Santana e seu grupo de alunas, orientandas e ex-orientandas, com o apoio da FAPESB, organizou referências sobre a História da Educação na Primeira República, levantando em acervos públicos e privados a documentação do período. Setor de Obras Raras da Biblioteca do Estado, Setor de Periódicos raros da mesma Biblioteca, Arquivo Público do Estado, Arquivo Municipal, Instituto Geográfico e Histórico do Estado, CEDIC - então na Biblioteca da Fundação Clemente Mariani, dentre outros, foram consultados e, localizada a documentação, digitalizada e reunida em acervo, foram preparados e publicados os dois primeiros volumes de documentação do período entre 1890 e 1930. Encontra-se no prelo o terceiro deles, todos componentes da Coleção Memória da Educação na Bahia, números 7, 8 e 9.

\section{História e documentos}

Nesse trabalho de pesquisa, tivemos como base do nosso trabalho com documentação, esteve sempre presente a interação com o professor Luis Henrique Dias Tavares, nosso consultor. Na primeira fase, na CPE utilizou-se o "Guia de Fontes para o Estudo da Educação no Brasil - Bahia”, por ele organizado e coordenado. Elaborado para o Centro Regional de Pesquisas Educacionais da Bahia e publicado pelo Instituto Nacional de Estudos e Pesquisas. - INEP, em 1957 - o único trabalho dos que foram então planejados para conhecer as Fontes para o Estudo da Educação pelo INEP. Seu trabalho serviu de modelo também para futuros trabalhos de organização de fontes. Em 2000, começando a Coleção Memória da Educação na Bahia, republicamos o livro citado.

Agora, nessa fase, tivemos o prazer de tê-lo como nosso consultor na UNEB, como bolsista DCR do CNPQ agregado ao projeto Memória. Hoje, a UNEB o tem como seu professor emérito; e seu trabalho auxiliou-nos inclusive na estruturação e implantação do nosso programa de pós-graduação em Educação e Contemporaneidade. A primeira atividade desenvolvida pelo Programa, já submetido à CAPES, foi um curso sobre História da Educação na República, dado pelo professor Dr. Luis Henrique, com a participação de convidados seus, e intercalado com a leitura de clássicos e a exibição do filme Tenda dos Milagres.

No livro citado não temos apenas um Guia de Fontes sobre Educação - , mas com ele se inaugura um modelo de como realizar este tipo de atividade. Mais adiante, sob a 
coordenação do próprio professor, e através da Secretaria de Educação da Bahia, foi elaborado um ementário da Educação na Bahia no Império; não publicado, do qual participou a professora Izabel Vilela, também membro, como Jacy Soares, as duas professoras de História e Filosofia da Educação da UFBA, já aposentadas, e eu mesma. Éramos as três do grupo de História da Educação organizado pelo professor Felipe Serpa, no âmbito do Mestrado em Educação da UFBa, em 1994. ${ }^{6}$ Este trabalho não chegou a ser publicado. Outro, dando seguimento ao primeiro deles, levantou a Legislação da Bahia na República também sob a forma de ementário, publicado pela Secretaria de Educação do Estado, em 1980.

No entanto, não foi ainda com o INEP, na década de 1950, que se deu início ao estudo da História da Educação no Brasil. Se fôssemos traçar uma trajetória da pesquisa e documentação sobre Educação no Brasil, teríamos que levar em conta outros estudos e obras de referência. Seria indispensável mencionar, no âmbito do próprio INEP, já na década de 1930, o convênio com o IBGE para a realização anual do Censo da Educação Nacional, - que produz uma gigantesca base de dados sobre Educação, matriculas, reprovação, abandono e conclusões.

Outros estudos realizados pelo INEP foram publicados desde então, sendo digno de nota o seu registro e publicação pela Revista Brasileira de Estudos Pedagógicos. Na mesma década de 1950, sob a direção de Anísio Teixeira, a organização do Centro Brasileiro de Pesquisas Educacionais e seus Centros Regionais realizaram estudos e experimentações na área da educação.

Num levantamento preliminar, encontramos da autoria do professor Luis Henrique mais dois livros publicados também pelo INEP - no caso CRPE da Bahia: "Súmula Educacional Bahiana até 1930"7 e "Duas reformas de Educação do Projeto Liberal", nos quais analisa as reformas de Sátiro Dias e de Manoel Vitorino, este mais próximo do pensamento de Ruy Barbosa como expresso no Parecer sobre a Educação Primária, de 1884. Encontramos, ainda, um texto de introdução ao que seria outro estudo encomendado pelo INEP, o Sistema Educacional Bahiano. ${ }^{9}$ Este material nos foi encaminhado pelo INEP em 1998, quando pedimos a sua localização. Apenas a introdução nos foi enviada.

Reconstruído o INEP, tivemos oportunidade de encontrar e guardar, digitalizados, a maioria dos números da Revista Brasileira de Estudos Pedagógicos do período de Anísio Teixeira na sua direção. Aqui encontramos uma enorme diversidade de artigos, de documentos, de registro de resultados de pesquisa, de proposições para a política nacional, de notícias, que mostra a enorme capacidade de produção e discussão sobre educação no Brasil que o grupo liderado por Anísio Teixeira teve e provocou. Entre o material encontrado, temos notícias sobre o Centro Educacional Carneiro Ribeiro - Escola Parque, sobre a Escola Experimental do INEP na Bahia e das atividades do Instituto aqui, na capacitação de professores de todo o interior do Estado da Bahia. O acervo documental do INEP na Bahia não foi encontrado ainda. Estamos à sua procura por dois anos. Mas encontramos seus rastros, tanto em documentação cedida pela pesquisadora do INEP, professora Regina Espinheira, que inclusive nos cedeu obras de sua autoria e de outros colegas da época; e a influência do órgão na educação foi possível encontrar na documentação guardada na Secretaria Acadêmica da Escola Parque, onde estão as fichas dos professores vindos diversos municípios para participar dos treinamentos, a programação de carga horária dos professores da Escola Parque - comprovando a natureza 
das atividades desenvolvidas, convênios então realizados, relatórios das diretoras das Escolas-Classe, Frequência dos alunos, mapas de resultados de aprendizado, proposição de formas de desseriação, entre outras coisas. Foi realizado um levantamento preliminar do material encontrado na Secretaria; e o levantamento dos livros publicados pelo INEP e utilizados nas capacitações dos professores existentes na biblioteca já foi iniciado. Falta todo o trabalho de organização dos arquivos das Escolas Classe. Os resultados preliminares estão sendo reunidos para publicação do Grupo Memória em conjunto com o CEDEM, parceiro na organização do acervo.

O trabalho em conjunto com o HISTEDBR, a UESB e a PUC-SP nos permitiu uma maior aproximação com os grupos e, em especial, com seus membros; e com formas de organização dos resultados de trabalhos de pesquisa, tanto através do projeto Navegando (Do HISTEDBR) como através da sistematização e publicação dos resultados de pesquisa nas Jornadas e Seminários e na Revista do Grupo HISTEDBR. Além disto, conhecemos o trabalho do Museu Pedagógico, da Universidade Estadual do Sudoeste da Bahia.

O enorme aprendizado tem sido, para nós, a possibilidade de retornar aos estudos sobre Anísio Teixeira e sua atuação, na Bahia e no Brasil, no chamado "intervalo democrático". A criação da Fundação para o Desenvolvimento da Ciência na Bahia ${ }^{10}$, a primeira do Brasil, criada e instalada entre 1947 e 1951, tendo Dr. Anísio como seu Secretário Executivo; a prévia criação e instalação de um Fundo para as atividades de pesquisa e formação de pesquisadores. Formado com um percentual da renda de impostos do Estado, o fundo financiou desde a data da criação e instalação da Fundação as atividades de pesquisa na área da Educação, das Ciências e da Saúde. 50\% dos seus recursos foram dirigidos para os estudos da área da Saúde, em especial de Medicina Tropical, então realizados no Governo do Estado da Bahia através da Fundação Gonçalo Muniz. O relatório da Fundação foi apresentado por Thales de Azevedo em 1966 ao governador Luis Viana Filho quando este cria a Secretaria da Ciência e Tecnologia, em 1969; Secretaria que é extinta já em 1971. No relatório de Thales temos a relação completa de todos os pesquisadores que receberam bolsa de estudos e auxílio à pesquisa até 1966, com o título do trabalho publicado ou da pesquisa realizada.

Entre os trabalhos relacionados por Thales de Azevedo, o projeto de pesquisa realizado entre 1950 e 1952 - A PESQUISA SOBRE A VIDA SOCIAL NO ESTADO DA BAHIA, e realizada em cooperação com o Programa de Pesquisas Sociais do Estado da Bahia-Columbia University, o Projeto Colúmbia. Thales de Azevedo relaciona os resultados de pesquisa decorrentes dessa cooperação com Universidade de Colúmbia, publicados em diversas revistas de pesquisa e em anais de eventos nacionais e internacionais. O material relacionado como resultante do Colúmbia foi grandemente localizado pelo grupo Memória e entregue para divulgação conjunta com o Histedbr e o Museu Pedagógico.

Em nossa visão, a Fundação para o Desenvolvimento da Ciência na Bahia é um primeiro ensaio do que viria a ser o Centro Brasileiro de Pesquisas Educacionais, em conjunto com os Centros Regionais a ele vinculados. Aqui se experimentou a pesquisa e a discussão de temas de interesse da comunidade da área da Educação e das Ciências sociais como um todo e serviu de embrião a um sistema de pesquisa na área de Ciência e Tecnologia na Bahia, abortado pelos diversos períodos de governo de Antonio Carlos Magalhães. ${ }^{11}$ 
Em suma, reafirmamos, nesta conclusão, nosso entendimento de que a pesquisa sobre História da Educação na Bahia - e no Brasil - não começa nem se esgota com as Universidades e seus Programas de pós-Graduação. Centros diversos de pesquisa e pesquisadores diversos produziram e ajudaram a construir este conhecimento. Aqui neste texto, queremos homenagear o professor Dr. Luis Henrique Dias Tavares, nosso permanente consultor, que, no Centro Regional de Pesquisas do INEP ou na sua permanente atividade de pesquisa, nos estimulou e serviu de exemplo sobre como criar as bases para o trabalho do estudioso da História da Educação.

Pesquisador cuidadoso, que não só desenvolveu uma intimidade com os acervos da Bahia no Arquivo Público do Estado, como ajudou, através de sua ação direta, na sua organização e preservação enquanto seu diretor. Seus trabalhos sobre História da Bahia, na medida em que se debruçam sobre os acervos existentes, nos permitem conhecer as causas populares, como nos seus trabalhos fundamentais sobre a Revolução dos Alfaiates, ou sobre o levante dos Periquitos no pós Independência da Bahia. Nos ajuda, assim, a desfazer mitos sobre os documentos escritos guardados como fonte apenas para a História dos Vencedores. Professor de História do Colégio Estadual da Bahia - Central; Professor de História da Faculdade de Filosofia da UFBA, Diretor por mais de 10 anos do Arquivo Público do Estado da Bahia, Diretor de Ensino Superior e Cultura da SEC no governo Luis Viana, cassado e preso em 1968, na crise do AI5. Sob sua responsabilidade, se deu a criação do sistema de bibliotecas do Estado da Bahia; e a construção da então Biblioteca Central do Estado da Bahia, e a disseminação de outras no interior do Estado.

Pesquisador disciplinado, de olhar atento, estudioso das causas populares: Os Alfaiates, os Periquitos, o Tráfico clandestino de escravos, o antigo repórter d'O Momento - Jornal dos comunistas existente na década de 1950 - nos ajuda a compreender que a História não tem mão única.

\section{Referências}

BAHIA, Governo do Estado, Fundação para o Desenvolvimento da Ciência na Bahia . Atuação no período 1951 - 1965 e Relatório de 1966. Bahia, 1967.

MENEZES Jaci e Mello, Alba Maria Guedes - Anais do Seminário de Experiências Inovadoras. Coleção Memória da Educação na Bahia, volume 02. Salvador, EDUNEB.

MENEZES, Jaci Maria Ferraz de ,"Educação e trajetórias de negros na Bahia: inclusão, exclusão e resistência". in Amorim, Lima $\mathrm{Jr}$ e Menezes, Educação e Contemporaneidade: processos e metamorfoses". Rio, Quartet, 2009. Ver Cadernos do IAT no. Especial sobre Anísio Teixeiera, 1987. Republicado na Revista da FAEEBA número 13, 2000, em www.revistadafaeeba.uneb.br. 
MENEZES, Jaci Maria Ferraz de - "Igualdad,y libertad, pluralismo y ciudadania: El acceso a La educación de negros y mestizos em Bahia", tese defendida na Universidade Católica de Córdoba, Argentina, como bolsista da OEA, em 1997. Disponível no site do Grupo Memória www.promeba.uneb.br

Tavares, Luis Henrique Dias - Evolução Educacional Bahiana (Súmula até 1930), in Arquivos da Universidade da Bahia, Faculdade de Filosofia, volume VI, 1957-1958.

TAVARES, Luis Henrique Dias - "O Sistema Educacional Bahiano. INEP MEC. Local Arquivo caixa 96, série Pesquisa.

TAVARES, Luis Henrique Dias Duas Reformas da Educação na Bahia. 1895 - 1925. Salvador, Bahia, INEP- Centro Regional de Pesquisas Educacionais.

TAVARES, Luis Henrique dias Guia de Fontes para o Estudo da Educação no Brasil Bahia. Coleção Memória da Educação na Bahia, volume 01. Salvador, EDUNEB.

Notas:

1 Doutora em Ciências da Educação e professor Pleno da Universidade do Estado da Bahia, coordena juntamente com a professora Doutora Elizabete Conceição Santana o Grupo de Pesquisas Memória da Educação na Bahia. email para comunicação: jacimnz@hotmail.com

${ }^{2}$ Levamos estes dados para o nosso trabalho de doutorado, e concluímos a tese "Igualdad,y libertad, pluralismo y ciudadania: El acceso a La educación de negros y mestizos em Bahia", defendida na Universidade Católica de Córdoba, Argentina, como bolsista da OEA, em 1997. Disponível no site do Grupo Memória www.promeba.uneb.br

${ }^{3}$ Os resultados encontrados levantavam nova questão para a pesquisa: se fora da escola: como aprendem? Porque do nosso curso de pedagogia tinha ficado o conhecimento de que todas as pessoas aprendem, que o aprender era intrínseco ao fazer quotidiano das pessoas. Procuramos responder a esta nova questão em pesquisa realizada com o apoio da Fundação Ford através do grupo A Cor da Bahia, ao qual estivemos associados um tempo. Seus resultados analisados para o Concurso de Professor Pleno da Universidade do Estado da Bahia, e publicados em capítulo do livro. Ver "Educação e trajetórias de negros na Bahia: inclusão, exclusão e resistência". in Amorim, Lima Jr e Menezes, Educação e Contemporaneidade: processos e metamorfoses". Rio, Quartet, 2009.

${ }^{44}$ Ver Cadernos do IAT no. Especial sobre Anísio Teixeiera, 1987. Republicado na Revista da FAEEBA número 13, 2000, em www.revistadafaeeba.uneb.br.

${ }^{5}$ Publicamos os Anais do Seminário de Experiências Inovadoras na coleção Memória da Educação na Bahia, volume 02. O número 01 foi a republicação do Guia de Fontes para o Estudo da Educação no Brasil - Bahia - do professor Luis Henrique Dias Tavares.

6 Participamos, Jaci Menezes e Izabel Vilela, de um seminário organizado pelo INEP em 1994 , no qual apresentamos documento elaborado pelo grupo formado pelo professor Felipe Serpa, Izabel Vilela, JAcy Soares e Jaci Menezes. Não publicado. 
7 Dias Tavares, Luis Henrique - Evolução Educacional Bahiana (Súmula até 1930), in Arquivos da Universidade da Bahia, Faculdade de Filosofia, volume VI, 1957-1958.

${ }^{8}$ DIAS TAVARES, Luis Henrique Dias Tavares, Duas Reformas da Educação na Bahia. 1895 - 1925. Salvador, Bahia, INEP-Centro Regional de Pesquisas Educacionais.

${ }^{9}$ TAVARES, Luis Henrique Dias - “O sistema Educacional Bahiano. INEP MEC, local no arquivo caixa 96, série Pesquisa.

${ }^{10}$ Ver Governo do Estado, Fundação para o Desenvolvimento da Ciência na Bahia . Atuação no período 1951 - 1965 e Relatório de 1966. Bahia, 1967.

111971 a 1974; 1979 a 1982; 1991 a 1994; e mais, nos intervalos, dos seus correligionários João Durval Carneiro - 1983 a 1986; Antonio Imbassahy, César Borges e Paulo Souto, 1995 a 1998; 1999 a 2001; 2002 a 2005.

Recebido: fevereiro-16 $\quad$ Aprovado: $\quad$ março-16 